Mycologia, 98(4), 2006, pp. 550-559.

(C) 2006 by The Mycological Society of America, Lawrence, KS 66044-8897

\title{
New findings of Neurospora in Europe and comparisons of diversity in temperate climates on continental scales
}

David J. Jacobson ${ }^{1}$

Department of Biological Sciences, Stanford University, Stanford, California 94305-5020 and Department of Plant and Microbial Biology, University of California, Berkeley, California 94720-3102

Jeremy R. Dettman ${ }^{2}$

Rachel I. Adams ${ }^{3}$

Department of Plant and Microbial Biology, University of California, Berkeley, California $94720-3102$

Cornelia Boesl

Shahana Sultana ${ }^{4}$

Till Roenneberg

Martha Merrow ${ }^{5}$

Institute for Medical Psychology, Centre for Chronobiology, Goethestraße 31, Ludwig Maximilians University München, 80336 München, Germany

Margarida Duarte

Isabel Marques

Alexandra Ushakova

Patrícia Carneiro

Arnaldo Videira

Instituto de Biologia Molecular e Celular (IBMC), and Instituto de Ciências Biomédicas Abel Salazar, (ICBAS) Universidade do Porto, Portugal

Laura Navarro-Sampedro

María Olmedo

Luis M. Corrochano

Departamento de Genética, Facultad de Biología, Universidad de Sevilla, Avenida Reina Mercedes 6, Apartado 1095, E-41080 Sevilla, Spain

John W. Taylor

Department of Plant and Microbial Biology, University of California, Berkeley, California 94720-3102

Abstract: The life cycles of the conidiating species of Neurospora are adapted to respond to fire, which is reflected in their natural history. Neurospora is found commonly on burned vegetation from the tropic and

\footnotetext{
Accepted for publication 14 Jul 2006.

${ }^{1}$ Corresponding author. E-mail: djjacob@stanford.edu

${ }^{2}$ Present address: Department of Botany, University of Toronto, Mississauga, Ontario, L5L 1C6 Canada.

${ }^{3}$ Present address: Department of Biological Sciences, Stanford University, Stanford, California 94305-5020.

${ }^{4}$ Present address: Internal Medicine I, Klinikum Grosshadern Marchioninistr 15, Ludwig Maximilians University München, 81377 München, Germany.

${ }^{5}$ Present address: Biological Centre, Chronobiology, University of Groningen, Postbus 14, 9750AA Haren, The Netherlands.
}

subtropical regions around the world and through the temperate regions of western North America. In temperate Europe it was unknown whether Neurospo$\mathrm{ra}$ would be as common as it is in North America because it has been reported only occasionally. In 2003 and 2004 a multinational effort surveyed wildfire sites in southern Europe. Neurospora was found commonly from southern Portugal and Spain $\left(37^{\circ} \mathrm{N}\right)$ to Switzerland $\left(46^{\circ} \mathrm{N}\right)$. Species collected included $N$. crassa, N. discreta, N. sitophila and $N$. tetrasperma. The species distribution and spatial dynamics of Neurospora populations showed both similarities and differences when compared between temperate Europe and western North America, both regions of similar latitude, climate and vegetation. For example the predominant species in western North America, N. discreta phylogenetic species 4B, is common but not predominant in Europe, whereas species rare in western North America, N. crassa NcB and N. sitophila, are much more common in Europe. The meiotic drive element Spore killer was also common in European populations of N. sitophila and at a higher proportion than anywhere else in the world. The methods by which organisms spread and adapt to new environments are fundamental ecosystem properties, yet they are little understood. The differences in regional diversity, reported here, can form the basis of testable hypotheses. Questions of phylogeography and adaptations can be addressed specifically by studying Neurospora in nature.

Key words: ecology, fire, meiotic drive, natural history, phylogentic species, Spore killer

\section{INTRODUCTION}

The conidiating species of the ascomycete fungus Neurospora, as a group, have been considered to be primarily tropical or subtropical with a complete longitudinal distribution (Turner and Perkins 1988, Turner et al 2001). These particular Neurospora species are well adapted to grow and sporulate on the surface of fire-scorched vegetation. Recent field surveys, however, have found that Neurospora commonly occupies an entirely different ecological niche, in dry and/or cold habitats. Within this new geographic range, western North America from New Mexico $\left(34^{\circ} \mathrm{N}\right)$ to Alaska $\left(64^{\circ} \mathrm{N}\right)$ (Jacobson et al 2004), Neurospora was found under the bark of firedamaged trees. This discovery has raised questions 
about the occurrence of Neurospora in other temperate regions.

The purpose of this study was to determine whether Neurospora is common in temperate regions of Europe. We hypothesized that the niche under the bark of burned vegetation had been overlooked in Europe as it was in North America. In autumn 2003 a multinational effort searched for Neurospora in fire sites across southern Europe after a summer of unusually devastating wildfires. Additional collections were made in 2004.

Most published accounts of Neurospora in temperate regions were anecdotal (see Jacobson et al 2004). In Europe Neurospora most often has been associated with bakeries, (Legan 1993, Perkins 1991, Perkins and Turner 1988, Yassin and Wheals 1992). High temperatures and the presence of easily colonized substrates that usually are associated with bakeries may allow Neurospora to grow in locations that traditionally were considered outside the geographic distribution of this fungus. However observations of Neurospora in nature have been sporadic in Europe with no systematic surveys or descriptions of populations on the scale of studies in temperate North America.

Individuals collected in Europe were identified with both biological and phylogenetic species recognition methods that have been developed for the outbreeding species of Neurospora. Phylogenetic species recognition also provided a preliminary indication of genetic diversity within species. The comparison of the isolates collected in this study with those from North America and throughout the world highlights differences in the ecology of Neurospora and the diversity of Neurospora populations in temperate climates on different continents.

\section{MATERIALS AND METHODS}

Collection, culturing and species identification.-An international consortium was formed to survey for Neurospora in Europe in summer 2003 during which an unusually intense heat wave led to devastating wildfires. Fire progression was followed and fire maps obtained from the Global Fire Monitoring Center website, http:// www.fire.uni-freiburg.de/current/globalfire.htm, and links therein. Satellite photos were obtained when possible from the Moderate Resolution Imaging Spectroradiometer (MODIS) Rapid Response system, nearreal-time production website, http://rapidfire.sci.gsfc. nasa.gov/production. These maps and photographs were used to locate easily accessible and widely distributed sites across southern Europe. Initial surveys were made in Portugal in early Sep 2003. Systematic field work was conducted in late Sep and early Oct 2003 at sites in Switzerland, northern Italy, southern France and northern Spain. Additional collections from Sapiãos, Portugal, and Seville, Spain, were made respectively in Sep and Oct 2004.

Methods of handling isolates, including collecting, initial culturing, subculturing of single conidia and storage, were exactly as described in Jacobson et al (2004). A field sample of conidia was collected from a sporulating colony onto sterile filter paper, which then was placed in a sterile envelope. One colony per plant was sampled for up to 45 isolates per site. In addition, where possible, two to seven isolates from the same plant were collected from one or two plants per site. Representative isolates of each species found at each site (both mating types when possible), and strains (TABLE I see below) have been deposited in the Fungal Genetic Stock Center (FGSC), Kansas city, Missouri 64110 (http://www.fgsc.net) under accession numbers 1001010059.

Recent taxonomic work (Cai et al 2006, García et al 2004) has not changed the status of the conidiating species of Neurospora. Therefore biological species recognition was used to identify isolates to species with a three-step process following methods outlined in Perkins and Turner (1988): (i) Assessment of heterothallism: A single conidium subculture from each isolate was allowed to grow on Vogel's minimal medium N (Davis 2000) at $25 \mathrm{C}$ for $7-10 \mathrm{~d}$ to test for self-fertility. Perithecia from each self-fertile isolate were dissected to determine the number of ascospores per ascus. All isolates with four ascospores per ascus were concluded to be $N$. tetrasperma. (ii) Mating-type (mat) determination: Each self-sterile (heterothallic) isolate was crossed to both mat $A$ and mat a species tester strains of $N$. crassa that contain the fluffy mutation (FGSC strains 6682 and 6683, respectively). Conidia of unknown isolates (males) were used to fertilize protoperithecia of the tester strains (females) growing on Petri dishes of Westergaard's synthetic crossing medium (Davis 2000). Fertilization was successful when conidia were applied to a small region of the tester colony, so that a single female tester on a $9 \mathrm{~cm}$ diam plate could be fertilized with up to 30 different isolates. A darkening and swelling of protoperithecia indicated a mating reaction after $2-4 \mathrm{~d}$ incubation at $25 \mathrm{C}$. A positive mating reaction on one female tester was obtained for each isolate, thus revealing mating type. (iii) Mating with species testers: When crossed to the $N$. crassa tester any isolate that produced $>50 \%$ black ascospores after 7-10 d postfertilization was classified as N. crassa (Perkins and Turner 1988). Isolates that produced only hyaline, unviable ascospores or no spores at all were judged not to be $N$. crassa. This response also confirmed that none of these isolates were $N$. intermedia, which routinely produces $5-10 \%$ black ascospores with the $N$. crassa tester strains (Perkins and Turner 1988). Each isolate was crossed, again as a male, to plates of tester strain females of the appropriate mating type for both $N$. sitophila (FGSC 5940 mat $A$ or 5941 mat a) and $N$. discreta (FGSC 3228 mat A or 4378 mat a). Fertility to these testers was mutually exclusive. Production of black ascospores was limited to crosses with one and only one of the species testers; no isolate made black ascospores with more than one tester. In addition no isolate was infertile with all Neurospora species testers. 
TABLE I. European isolates of Neurospora used in phylogenetic analyses

\begin{tabular}{|c|c|c|c|}
\hline \multicolumn{2}{|c|}{ Species, clade and isolate numbers } & \multirow[b]{2}{*}{ Mating type } & \multirow[b]{2}{*}{ Country, site } \\
\hline FGSC number & D number ${ }^{\mathrm{a}}$ & & \\
\hline \multicolumn{4}{|l|}{ N. crassa $\mathrm{NcB}$} \\
\hline 10049 & & mat $A$ & Spain, Platja d'Aro \\
\hline 10050 & & mat $A$ & Spain, Platja d'Aro \\
\hline 10033 & & mat $a$ & Spain, Macanet de la Selva \\
\hline 10043 & & mat $a$ & Spain, Seros \\
\hline 10044 & & mat $A$ & Spain, Seros \\
\hline 10045 & & mat $a$ & Spain, Seros \\
\hline 10046 & & mat $A$ & Spain, Seros \\
\hline 10017 & & mat $A$ & Portugal, Troviscal Sertã \\
\hline 10018 & & mat $A$ & Portugal, Penedo Furado \\
\hline 10020 & & mat $A$ & Portugal, Tapada de Mafra \\
\hline 10021 & & mat $a$ & Portugal, Tapada de Mafra \\
\hline 10024 & & mat $A$ & Portugal, Tapada de Mafra \\
\hline 10027 & & mat $a$ & Portugal, Monchique \\
\hline 10028 & & mat $a$ & Portugal, Monchique \\
\hline 10036 & & mat $a$ & Italy, Turchino Est. \\
\hline 10037 & & mat $a$ & Italy, Turchino Est. \\
\hline 10038 & & mat $a$ & Italy, Turchino Est. \\
\hline 10040 & & mat $a$ & Italy, Turchino Est. \\
\hline 10042 & & mat $a$ & Italy, Turchino Est. \\
\hline 10051 & & mat $A$ & Italy, Genoa \\
\hline 10054 & & mat $a$ & Italy, Genoa \\
\hline 10056 & & mat $A$ & Italy, Genoa \\
\hline \multicolumn{4}{|l|}{ N. discreta } \\
\hline 9991 & $\mathrm{D} 221$ & mat $A$ & Spain, Macanet de la Selva \\
\hline 9990 & $\mathrm{D} 220$ & mat $A$ & Portugal, Monchique \\
\hline 9989 & D218 & mat $A$ & Portugal, Monchique \\
\hline 10025 & & mat $a$ & Portugal, Monchique \\
\hline 10010 & & mat $a$ & Portugal, Boticas \\
\hline 10011 & & mat $a$ & Portugal, Boticas \\
\hline 9986 & $\mathrm{D} 215$ & mat $a$ & Portugal, Boticas \\
\hline 9987 & D216 & mat $A$ & Portugal, Boticas \\
\hline 9988 & $\mathrm{D} 217$ & mat $a$ & Portugal, Boticas \\
\hline 10012 & & mat $a$ & Portugal, Boticas \\
\hline 10013 & & mat $A$ & Portugal, Boticas \\
\hline 10014 & & mat $A$ & Portugal, Boticas \\
\hline 9992 & D224 & mat $A$ & Switzerland, Leuk \\
\hline 9993 & $\mathrm{D} 225$ & mat $A$ & Switzerland, Leuk \\
\hline
\end{tabular}

${ }^{\text {a }} \mathrm{D}$ numbers refer to isolate numbers given by Dettman et al (2006) in the phylogenetic study of $N$. discreta.

Characterization of the genetic diversity among N. crassa and N. discreta strains.-Phylogenetic analyses of N. crassa and $N$. discreta have revealed genetically distinct clades within these species (Dettman et al 2003a, 2006). To assign European isolates to these clades, or to discover other clades within these biological species, sequence was obtained for three diagnostic polymorphic DNA regions (Dettman et al 2003a). Sequences of the three polymorphic regions (unlinked, noncoding loci that flank microsatellites [TMI, TML, and DMG]) were obtained with methods described by Dettman et al (2003a). Sequences were aligned manually, because of the presence of microsatellites and insertion/deletion gaps (indels) within these loci. Microsatellite sequences were omitted from the analyses. Fourteen of 17 European $N$. discreta isolates were analyzed (excluding multiple isolates of the same mating type from the same plant), as were $22 \mathrm{~N}$. crassa isolates from all sites where $N$. crassa was present, including multiple isolates of different mating type where available (TABLE I). The only two $N$. crassa isolates obtained from western North America (Montana; FGSC 8571 and W-864) (Jacobson et al 2004) also were included. The sequences have been deposited in GenBank under accession numbers DQ442288-DQ442377.

The sequences of the three loci were combined into a single dataset because previous use of the partition homogeneity test showed a lack of incongruence (Dettman 
et al 2003a, 2006). Separate maximum parsimony trees were calculated for $N$. discreta and N. crassa with PAUP* (version 4.0b10, Swofford 2003). Analysis of European N. discreta isolates in relation to worldwide collections of $N$. discreta sensu lato has been reported by Dettman et al (2006). For comparative purposes the $N$. crassa dataset included sequences of the three loci from a subset of 37 of the $N$. crassa strains included in Dettman et al (2003a). No outgroups were included, because Dettman et al (2003a) clearly showed that $N$. crassa is a well supported phylogenetic species. Maximum parsimony bootstrapping for $N$. crassa was performed with heuristic searches (1000 replicates, simple stepwise addition, tree bisection-reconnection branch swapping, MAXTREES $=100$ ).

\section{RESULTS}

The occurrence of Neurospora in wildfire sites.-The yellow to orange colonies of Neurospora conidiating on the surface of woody and herbaceous plants killed by fire were recognized easily (FIG. 1). Neurospora was found to be common at some sites, while being relatively rare at others sites (TABLE II, FIG. 2). The 14 sites surveyed extend over ca. $1650 \mathrm{~km}$ in a path leading generally northeast from southern Portugal $\left(37^{\circ} 18^{\prime} \mathrm{N}, 8^{\circ} 35^{\prime} \mathrm{W}\right)$ to Switzerland $\left(46^{\circ} 19^{\prime} \mathrm{N}, 7^{\circ} 38^{\prime} \mathrm{E}\right)$. The number of isolates collected totals 247 and includes the species $N$. crassa, $N$. discreta, $N$. sitophila and $N$. tetrasperma. At five of the 14 sites collections were from a single species of Neurospora, whereas collections at the other nine sites yielded multiple species. Most of these isolates (195) were single colonies collected from an individual plant. Multiple colonies (2-7) were sampled from 13 plants across five sites. Eleven of these plants yielded a single species, but two plants were colonized by two Neurospora species each. Although no systematic attempt was made to gauge the level of clonality or measure intraspecific genetic diversity among the isolates, multiple genotypes of the same species were found on five of the plants inhabited by a single species of Neurospora (see below).

Spore killer in N. sitophila.-Isolates identified as $N$. sitophila could be separated into two classes based on crosses with the species tester strains. One class produced 90-95\% black ascospores, whereas the other produced $50 \%$ black ascospores with the remaining spores being hyaline, significantly smaller and unviable. When perithecia from these crosses were dissected microscopically, nearly every ascus showed a 4:4 black:hyaline ascospore pattern (FIG. 3). This pattern is the hallmark of Spore killer meiotic drive in Neurospora (Raju

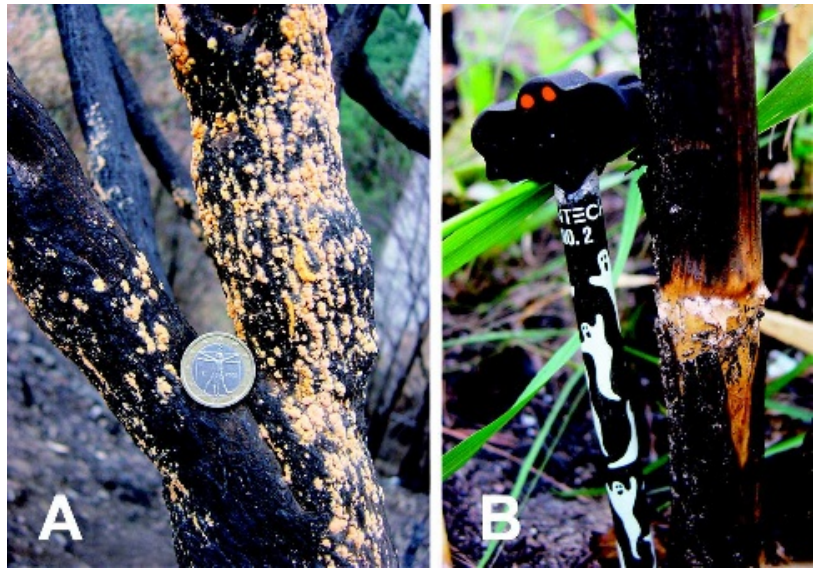

FIG. 1. Neurospora growing and sporulating on scorched vegetation in Europe. A. Extensive colonization of an unidentified shrub at Turchino Est., Italy. B. Localized sporulation limited to the node of cane-like grass at Seros, Spain.

2002). Because the tester strains of $N$. sitophila used (FGSC 5940 mat $A$ and 5941 mat a) are known to be sensitive to Spore killer, the killer component must be present in the European N. sitophila isolates.

A single spore killer element, Spore killer $(S k-1)$, has been described in N. sitophila (Raju 2002, Turner 2001). Research with $S k-1$ has shown that only killer $\times$ sensitive heterozygous crosses show killing; both homozygous crosses, killer $\times$ killer and sensitive $\times$ sensitive, show normal 8:0, black:hyaline, ascospores in each ascus. Therefore, to determine if the Spore killer in European isolates is $S k-1$ or a new element, each $N$. sitophila strain was crossed to $S k-1$ testers strains (FGSC 2216 mat $A$ or 2217 mat a). All European isolates that showed 4:4 killing when crossed to sensitive produced 8:0 asci when crossed to $S k$-1. Likewise all European isolates that produced 8:0 asci when crossed to sensitive showed 4:4 killing when crossed to $S k-1$. All killer European N. sitophila isolates, therefore, are $S k-1$; no new killer elements were apparent in these samples.

Fifty-four percent of the $N$. sitophila isolates collected (45 of 83) expressed the killer phenotype. The killer haplotype was present in six of the seven sites containing $N$. sitophila, and three of these contained both killer and sensitive haplotypes. However killer and sensitive haplotypes were not found together on any of the five plants from which multiple isolates of $N$. sitophila were recovered.

N. crassa.-A single maximum parsimony tree was produced from combined sequences of the TMI, TML, and DMG loci (FIG. 4). Included in the tree were representatives of the three major clades in 
TABLE II. The distribution of species of Neurospora across sites surveyed in Europe in 2003-2004 ${ }^{\mathrm{a}}$

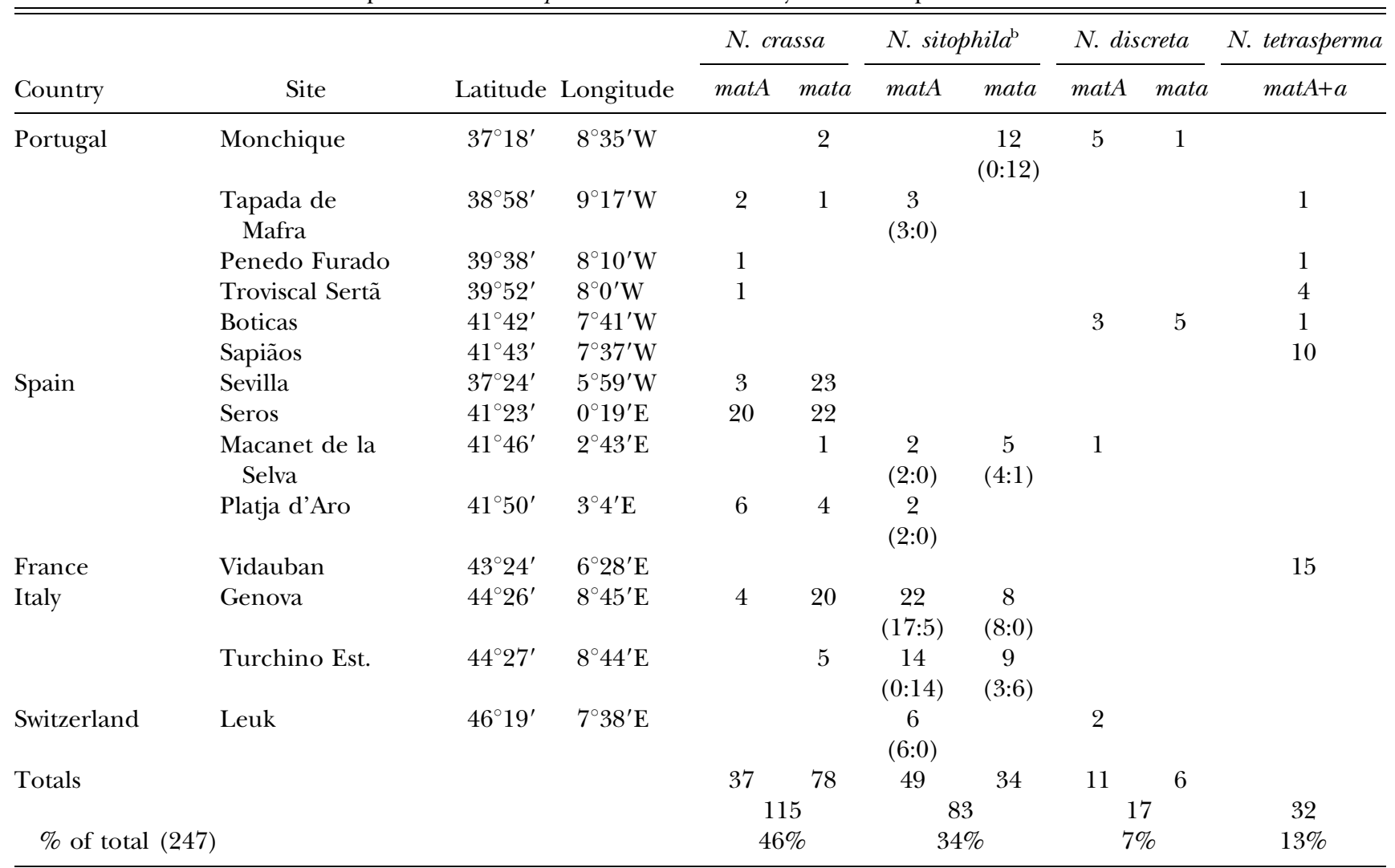

${ }^{a}$ All isolates are totaled here, including those collected from the same plant. No systematic attempt was made to identify clones which may have been repeatedly sampled. Characterization of a small number of genetic markers, for a limited number of isolates, was conducted for phylogenetic clade identification and tree construction (see TABLE I, FIG. 4 and text).

${ }^{\mathrm{b}}$ The ratio of $S k-1$ killer to sensitive isolates is in parentheses.

N. crassa, NcA, NcB and NcC (Dettman et al 2003a). Sequence was obtained for all three loci from 22 European isolates of $N$. crassa. All these isolates fell into the single, previously described clade NcB (TABLE I, Fig. 4).

The sequence of the TMI locus subsequently was obtained from the remaining 93 isolates of European $N$. crassa to associate each with the appropriate phylogenetic clade. TMI was chosen as a diagnostic locus because its sequence is clearly distinct between the NcB clade versus clades NcA and NcC. All 93 isolates fell within the $\mathrm{NcB}$ clade (data not shown). Of these 83 had TMI sequences that were essentially identical, including the number of microsatellite repeats. Ten isolates, all from Seville, Spain, were exceptional in having a single nucleotide polymorphism at base 119 in the microsatellite flanking sequence and a microsatellite with 5 rather than 12 repeats.

Although it was beyond the scope of this study to assess clonality of strains from the same plant, we did investigate the genotypes of multiple $N$. crass $a$ isolates collected from seven individual plants. When two polymorphic markers ( $m a t$ and TMI) were combined, five plants from Seville, Spain, revealed more than one genetically distinct individual of $N$. crassa per plant. In contrast the multiple isolates of $N$. crassa from the two other plants (from Seros, Spain, and Genoa, Italy) were monomorphic at both markers. This preliminary study indicated that more than one genetic individual could be present in very close spatial scales, as was reported by Powell et al (2004).

Phylogenetic species $4 B$ within the $\mathrm{N}$. discreta complex.-The European isolates of $N$. discreta sensu lato, as defined by biological species recognition, all were identified as belonging to phylogenetic species (PS) 4B (tree not shown, refer to Dettman et al 2006 FIG. 2 for relationships among phylogenetic species within the $N$. discreta complex). Of the six isolates sequenced here that were not analyzed by Dettman et al (2006), each had sequence identical to at least one isolate examined 


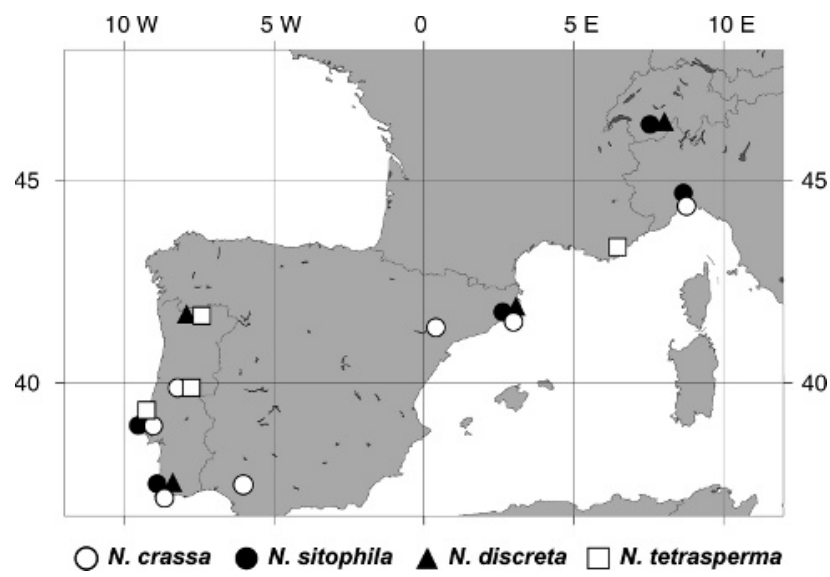

FIG. 2. Distribution of Neurospora biological species collected in Europe.

by Dettman et al (2006). Therefore no additional genetic diversity was found within PS $4 \mathrm{~B}$ or the European population, and PS $4 \mathrm{~B}$ is the only species of the $N$. discreta complex found in Europe to date.

\section{DISCUSSION}

Reports of the occurrence of Neurospora in Europe have been published sporadically over the past $160 \mathrm{y}$, beginning with its earliest description from France in 1843 (see Perkins 1991). Most of these descriptions have concentrated on Neurospora contamination of bakeries and their products; the most recent was Yassin and Wheals (1992). Not long after formal description of the genus by Shear and Dodge (1927), however, Ramsbottom and Stephens (1935) mentioned that Neurospora was found on other natural substrates, most notably burnt trees and gorse in Britain. Other anecdotal observations have suggested that Neurospora is not uncommon in Europe (e.g. D. Zickler, University Paris South, personal communication with D.D. Perkins, Stanford University). However, to our knowledge, this is the first study that systematically sampled Neurospora from natural habitats in Europe.

All five classically described, conidiating, biological species of Neurospora now have now been identified in Europe: $N$. crassa, $N$. discreta, $N$. intermedia, $N$. sitophila and N. tetrasperma. This is the first study to report $N$. discreta, whereas we did not find $N$. intermedia, which was reported by Ramsbottom and Stephens (1935). Recent work has further divided Neurospora into phylogenetic species and clades (Dettman et al 2003a, 2006). Of the eight phylogenetic species within the $N$. discreta complex only one (PS 4B) was identified among the European isolates

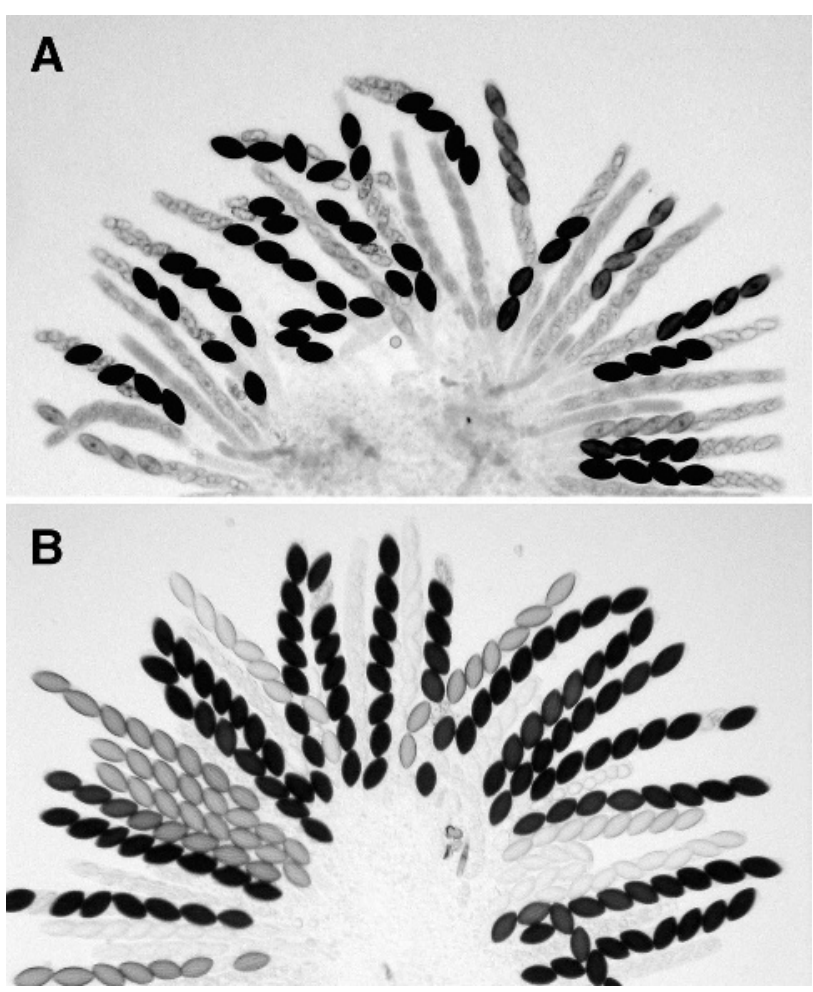

FIG. 3. Asci from crosses of European N. sitophila Spore killer strains. A. A cross heterozygous for $S k-1$ (killer $\times$ sensitive). Asci contain four normal size, maturing, viable Sk-1 ascospores and four hyaline, aborted sensitive ascospores. B. A homozygous (sensitive $\times$ senstive) cross for $S k$ 1. Asci contain eight normal size, maturing, viable ascospores. Homozygous $S k$ - 1 killer $\times$ killer crosses also show asci containing eight viable ascospores (Photomicrographs courtesy of N.B. Raju, Stanford University).

collected here. Two newly described phylogenetic species outside the $N$. discreta complex also were found to be distinct biological species (Dettman et al 2003b); neither of these species were found among the European isolates. Of the three distinct clades within $N$. crassa (NcA, NcB and $\mathrm{NcC}$ ), all new European N. crassa isolates fell into NcB. Based on these finer scale measures of genetic divergence among members of Neurospora, similarities and differences were assessed between the newly sampled populations from Europe and populations from other continents, including both temperate and tropical/ subtropical climates.

The similarity of Neurospora between Europe and southeastern, subtropical areas of the United States is also reflected in the overall species diversity and distributions. The complement of species and their frequency of collection are similar in Europe and southeastern United States (FIG. 5). This distribution is in stark contrast to populations of Neurospora in western North America, which are composed pre- 


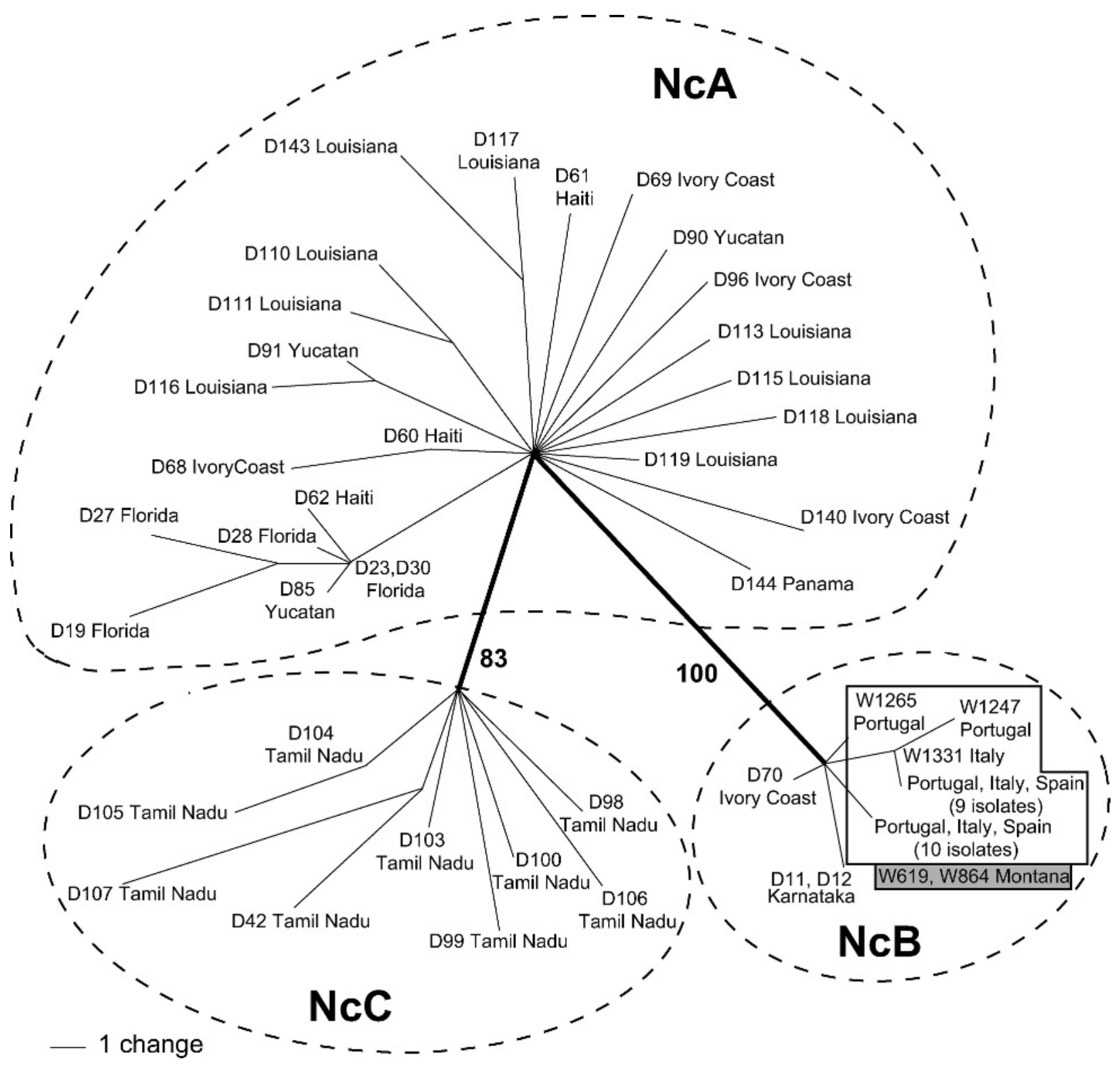

FIG. 4. The relationships among the three phylogenetic clades within N. crassa. Maximum parsimony, unrooted phylogram produced from the sequences of three combined loci. Numbers next to bold branches separating NcA, NcB and NcC clades indicate bootstrap support (1000 replicates). Taxon labels indicate strain number and geographic source; European strains from this study are shown within the box, and western North American strain from Jacobson et al (2004) are shown in the shaded box. All strains labeled with D numbers were sequenced as part of Dettman et al (2003a). One locus (TMI) was sequenced from an additional 93 European $N$. crassa isolates because this locus is diagnostic for $N$. crassa clade. All 93 isolates were placed definitively into NcB based on TMI sequence (data not shown).

dominantly of a single species in the $N$. discreta complex (PS 4B), with only rare occurrences of $N$. sitophila and N. crassa. Neurospora has been found at $64^{\circ} \mathrm{N}$ latitude in Alaska and as far as $45^{\circ} \mathrm{N}$ in Europe. Future collecting expeditions are planned to target even higher latitudes in Europe in the hope of learning more about the distribution of Neurospora species.

The absence of $N$. intermedia in our European collection was unexpected given reports in the literature (Ramsbottom and Stephens 1935, Yassin and Wheals 1992). For example Yassin and Wheals (1992) reported nine of 345 isolates $(<3 \%)$ as $N$. intermedia, eight of which were from nonbakery sources, including imported Indonesian ontjom. Moreover $N$. intermedia is by far the most common species collected world wide, particularly at latitudes $>30^{\circ} \mathrm{N}$ and $\mathrm{S}$ (China, Japan, Australia and New 


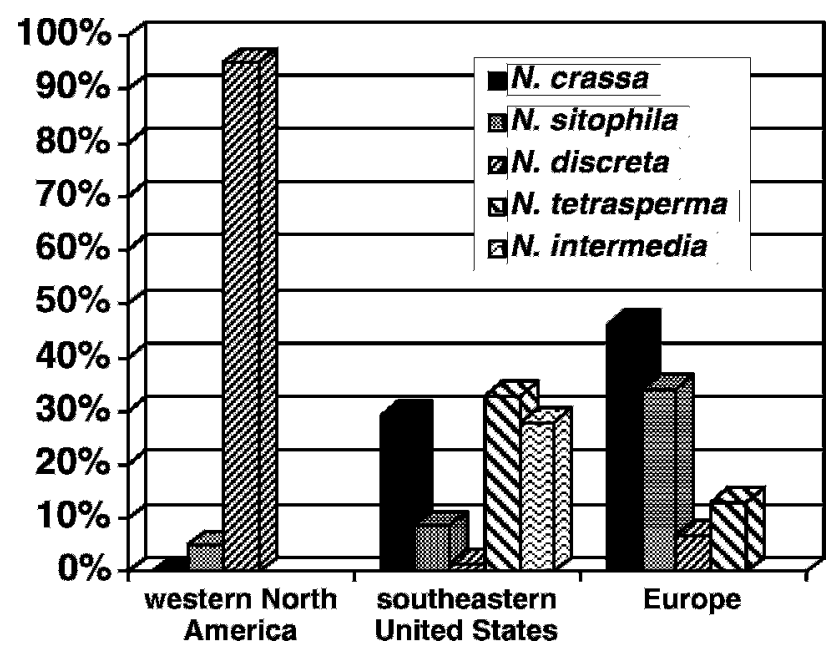

FIG. 5. Frequency of Neurospora biological species by region. Data for western North America taken from Jacobson et al (2004), data for southeastern United States taken from Turner (2001).

Zealand) (Turner et al 2001). Given that there are likely to be sources of $N$. intermedia in Europe, the lack of $N$. intermedia in our collections from temperate northern latitudes in Europe and western North America is intriguing but its significance cannot be assessed currently.

The physical appearance in nature of $N$. crassa and $N$. discreta from Europe and the southeastern US is remarkably similar and unlike that of $N$. discreta from western North America. However phylogenetic analysis of DNA sequences indicated that the European isolates of the two species were highly similar to those from temperate western North America and dissimilar to those found in the southeastern United States.

$N$. crass a clades $\mathrm{NcA}, \mathrm{NcB}$ and $\mathrm{NcC}$ are genetically distinct from one another but do not meet the strict criteria that would make them separate phylogenetic species (Dettman et al 2003a). These clades have distinct geographical distributions. NcA was widespread across the Caribbean basin and Africa. NcC was limited to the state of Tamil Nadu in India, and the rare isolates of $\mathrm{NcB}$ were limited to equatorial Africa and southern India. The addition of all the European and western North American isolates of $N$. crassa to clade $\mathrm{NcB}$ significantly changes the biogeography of the species. Now NcB also appears geographically widespread, similar to NcA, although its prevalence outside of Europe remains in question.

Distributions of NcA and $\mathrm{NcB}$ in the western hemisphere and Europe are nonoverlapping, but the clades do coexist in equatorial Africa. NcA and NcC, whose ranges overlap in southern India, have developed reproductive isolation phenotypes, which correlate with the genetic distance (Dettman et al 2003b; E. Turner, University of California at Berkeley, unpublished). No attempt was made in this or previous studies to characterize the reproductive relationships between members of the NcA and NcB clades; biological species recognition was limited to crossing European isolates to the species tester strains. We therefore do not know whether NcA and $\mathrm{NcB}$ show reproductive isolation anywhere in their range.

The $N$. discreta complex from Europe and North America also shows a combination of widespread and more narrowly distributed species. European $N$. discreta isolates, which represent only $7 \%$ of all collected European isolates, are placed phylogenetically within the predominant species in western North America, the widespread PS 4B. PS 4B however is phylogenetically distant from the two other $N$. discreta species in North America (i.e., N. discreta sensu stricto [Texas] and PS 7 [Florida, Mexico and Guatemala]).

Striking differences were seen in the growth habit and the morphology of colonies of Neurospora on natural substrates between the two temperate continents. As mentioned, Neurospora in Europe was commonly seen apparently growing on the surface of charred bark (FIG. 1A). In contrast extensive colonies of Neurospora were seen in western North America but always under the bark of woody plants. Only rarely, and after prolonged incubation periods, did the fungus erupt through the bark (Jacobson et al 2004, FIG. 1). The extensive amount of sporulation on the surface of burned bark, as seen in Europe, was never observed in western North America. Moreover recognizable colonies of Neurospora were not observed under the bark in Europe.

Neurospora in Europe grew on both charred woody and herbaceous plants, such as the grass in Spain (FIG. 1B). In contrast Neurospora was never observed in western North America on herbaceous plants. Although the latitude, climate, geography and vegetation are similar between Europe and temperate western North America, the growth habit and substrate of Neurospora in Europe are similar to those in tropical and subtropical areas, including Florida and Texas in the southern United States (Powell et al 2003, Turner and Perkins 1988, Turner et al 2001).

The proportion of N. sitophila Spore killer strains reported here for Europe is much higher (45 of 83, $54 \%$ ) than worldwide (77 of 469, 16\%) (FIG. 5) and might provide an opportunity to study the dynamics of Spore killers in nature and the effect of meiotic drive on populations. Existing data have been insufficient to determine the potential of Spore killer to become fixed in any population (Turner 2001), which makes the spatial and temporal dynamics of killer and 
sensitive haplotypes in European populations of great interest (Burt and Trivers 2006). Whether a stable equilibrium is maintained can be tested only where killer and sensitive coexist in the same populations, but $S k-1$ killer and sensitive haplotypes coexist from only 10 out of $92(11 \%)$ sites where Spore killer has been found outside of Europe: one in Hawaii, one in Vanuatu and eight in Tahiti. In Europe, as mentioned, killer and sensitive coexist in three of six sites with $S k-1$ frequency of 13-83\%. European Spore killer isolates also were reported by Yassin and Wheals (1992) who found that all nine of their bakery $N$. sitophila isolates were $S k-1$. Re-sampling of European $N$. sitophila populations over time might provide the data needed to understand Spore killer and meiotic drive in nature.

Together with the recent discovery of Neurospora in western North America (Jacobson et al 2004), documentation presented here of its occurrence in Europe firmly establishes it as a common inhabitant of temperate climates, perhaps worldwide. The broad distribution of $N$. discreta, particularly its longitudinal component, place it, along with $N$. crassa, among the handful of species that have the attributes to serve as evolutionary and ecological model organisms. There will be no lack of ecological questions because of the large gaps in our knowledge of the basic ecology of Neurospora and fire adapted fungi in general. The differences in regional diversity, reported here, can form the basis of testable hypotheses. Questions of phylogeography and adaptations specifically can be addressed with Neurospora: Where did these species of Neurospora originate and how did they arrive at their modern distributions? What role have human activities played in the current distribution of Neurospora lineages? Have populations of Neurospora changed genetically to adapt to local conditions, such as ambient temperature or photoperiod (Tan et al 2004)? How organisms spread and adapt to new environments are fundamental ecosystem properties, yet they are little understood. We hope that understanding of these fundamental features will come from studies of $N$. discreta that blend ecology and evolutionary biology with genetics and genomics.

\section{ACKNOWLEDGMENTS AND CONTRIBUTIONS OF AUTHORS}

D.J. conceived and coordinated the project with the assistance of J.T., M.M., T.R., A.V., and L.M.C. D.J., C.B. and S.S. collected and cultured most strains. M.D., I.M., A.U., P.C. and A.V. collected and cultured Portugal strains, identifying some. L.M.C., L.N.S. and M.O. collected in Seville and provided needed logistical help in locating other collection sites in Spain. D.J. identified or confirmed identification of all strains. J.D., R.A. and D.J. sequenced and performed phylogenetic analyses. D.J. analyzed the data and with J.T. wrote the paper. The work was supported by a grant from the US National Science Foundation to J.T. (DEB-0316710); by grants from the Deutsche Forschungsgemeinschaft and the Meyer-Struckman Stiftung to T.R.; by grants from Fundação para a Ciência e a Tecnologia to A.V.; and by grants from the Ministerio de Educación y Ciencia, Spain, (INIA RM2004-00007) and Junta de Andalucía (CVI 0119) to L.M.C. D.J. also is supported in part by US National Science Foundation grant MCB-0417282, awarded to David D. Perkins, Stanford University. We thank David Perkins for allowing part of this work to be completed in his laboratory and N.B. Raju for the photomicrographs used in FIG. 3.

\section{LITERATURE CITED}

Burt A, Trivers R. 2006. Genes in conflict: the biology of selfish genetic elements. Cambridge, Massachusetts: Belknap Press of Harvard University Press. 602 p.

Cai L, Heewon R, Hyde KD. 2006. Phylogenetic investigations of Sordariaceae based on multiple gene sequences and morphology. Mycol Res 110:137-150.

Davis RH. 2000. Neurospora: contributions of a model organism. New York: Oxford University Press. 333 p.

Dettman JR, Jacobson DJ, Taylor JW. 2003a. A multilocus genealogical approach to phylogenetic species recognition in the model eukaryote Neurospora. Evolution 57:2703-2720.

2006. Multilocus sequence data reveal extensive phylogenetic species diversity within the Neurospora discreta complex. Mycologia 98:437447.

- — - Turner E, Pringle A, Taylor JW. 2003b. Reproductive isolation and phylogenetic divergence in Neurospora: comparing methods of species recognition in a model eukaryote. Evolution 57:2721-2741.

García D, Stchigel AM, Cano J, Guarro J, Hawkworth DL. 2004. A synopsis and recircumscription of Neurospora (syn. Gelasinospora) based on ultrastructural and 28S rDNA sequence data. Mycol Res 108:1119-1142.

Jacobson DJ, Powell AJ, Dettman JR, Saenz GS, Barton MM, Hiltz MD, Dvorachek WH, Glass NL, Taylor JW, Natvig DO. 2004. Neurospora in temperate forests of western North America. Mycologia 96:66-74.

Legan JD. 1993. Mould spoilage of bread: the problem and some solutions. Int Biodeterior Biodegrad 32:33-53.

Perkins DD, Turner BC. 1988. Neurospora from natural populations: toward the population biology of a haploid eukaryote. Exp Mycol 12:91-131.

—_. 1991. The first published scientific study of Neurospora, including a description of photoinduction of carotenoids. Fung Genet Newsl 38:64-65.

Powell AJ, Jacobson DJ, Natvig DO. 2003. Variation among natural isolates of Neurospora on small spatial scales. Mycologia 95:809-819.

Raju NB. 2002. Spore killers: meiotic drive elements that distort genetic ratios. In: Osiewacz HD, ed. Molecular biology of fungal development. New York: Marcel Decker Inc. p 275-296.

Ramsbottom J, Stephens FL. 1935. Neurospora in Britain. Trans Brit Mycol Soc 19:215-220. 
Shear CL, Dodge BO. 1927. Life histories of and heterothallism of the red bread-mold fungi of the Monilia sitophila group. J Ag Res 34:1019-1042.

Swofford DL. 2003. PAUP*: phylogenetic analysis using parsimony (*and other methods). Version 4.0.b10. Sunderland, Massachusetts: Sinauer Associates.

Tan Y, Merrow M, Roenneberg T. 2004. Photoperiodism in Neurospora crassa. J Biol Rhythm 19:135-43.
Turner BC. 2001. Geographic distribution of Neurospora Spore killer strains and strains resistant to killing. Fung Genet Biol 32:93-104.

, Perkins DD, Fairfield A. 2001. Neurospora from natural populations: a global study. Fung Genet Biol 32:67-92.

Yassin S, Wheals A. 1992. Neurospora species in bakeries. J Appl Bacteriol 72:377-380. 